\section{TRICHLORETHYLENE ANAESTHESIA}

By Gordon Ostlere, M.A., M.B., B.Chir., D.A. Pp. vii +83 , with 5 illustrations. Edinburgh: E. \& S. Livingstone Ltd. 1953. 7s. 6d.

The small book is an analysis of the published work on trichlorethylene. The first chapter, on the history, describes in an interesting manner its introduction as a possible treatment for trigeminal neuralgia and, following an unfavourable reception in America, its re-assessment in this country as a potentially suitable non-inflammable anaesthetic for use in warfare. The chapter on pharmacology sets down the contradictory reports in a clear and unbiased way, the conflicting evidence being explained by the misuse of the drug in many of the earlier papers.

Throughout the book stress is properly laid on the correct use of trichlorethylene for maintenance of anaesthesia. However, it is surprising to read that the author considers that it is permissible to inject adrenaline while trichlorethylene is being administered, and also that he considers trilene is contra-indicated in children. Again, not everyone would agree that blind intubation under thiopentone-nitrous-oxide-oxygen-trilene sequence is to be recommended.

Apart from these debatable points trichlorethylene anaesthesia is a sound and readable monograph, being well laid out with adequate use of heavy type headings; full lists of references are given at the end of each chapter for those wishing to study the original articles quoted by the author.

D.C.

\section{SECOND ANNUAL REPORT ON STRESS}

By HaNs Selye, M.D., Ph.D., D.Sc., F.R.S., and Alexander Horava, M.D. Pp. 526, illustrated. Montreal: Acta Inc. 1952. \$10.

Like its predecessor, this volume is published as a guide to the literature bearing upon the senior author's concept of stress. The greater part of the book consists of classified indices designed to enable the reader to find references to recent literature. Since the concept of stress is a wide one, the scope of the book is immense, covering large fields of physiology and medicine. For this reason the value of the book greatly exceeds that which the title might suggest.

R.R.H.L.

\section{THE JOURNAL OF THE AMERIÇAN GERIATRICS SOCIETY}

A new journal, The Fournal of the American Geriatrics Society, has been started. The first number appeared in January 1953. The iournal will appear bi-monthly. The cost will be $\$ 2$ per annum. The agents for the United Kingdom are Baillière, Tindall \& Cox, Ltd., 7 and 8 Henrietta Street, London, W.C.2.
LOCAL ANALGESIA : ABDOMINAL SURGERY

By R. R. Macintosh, M.A., D.M., F.R.C.S., D.A., and R. BRYCE-SMITH, M.A., B.M., B.Ch., D.A. Pp. 94, with 88 illustrations. Edinburgh: E. \& S. Livingstone Ltd. I 953 . 22s. 6d.

This small book is a companion volume to the senior author's works on brachial plexus block and on lumbar puncture and spinal analgesia. It shares with them, terseness of style, delightful illustrations (many of them in colour) and excellent production. It owes its appearance largely to the revival of interest in local analgesia following the introduction of xylocaine.

The indications for local analgesia are given and include operations for strangulated hernia where vomiting is severe, lack of adequate supervision of the unconscious patient, and patients on whom a surgeon may be called on to operate unassisted by an anaesthetist.

The drugs recommended, with maximum doses which may safely be given to healthy adults, are procaine ( 2 g.), xylocaine (I g.), nupercaine (I 50 mg.) and amethocaine ( $150 \mathrm{mg}$.). The addition of $0.5 \mathrm{ml}$. of $\mathrm{I}$ in 1,000 adrenaline solution to the analgesic solution retards absorption, lessens toxicity and prolongs the analgesic effect.

The sensory pathways from the viscera and parietes are described and illustrated, while succinct accounts are given of the anatomy of the anterior abdominal wall, the inguinal canal, the intercostal and subcostal nerves and the iliohypogastric,ilioinguinal and genito-femoral nerves.

Of special interest is the description of the paravertebral spaces, and the authors state that if the lower seven thoracic and the first lumbar spaces on each side are infiltrated with solution, both the somatic and the splanchnic nerves, the latter by way of the rami communicantes, will be made insensitive, and the resulting analgesia of viscera and parietes will be equivalent to that provided by a subarachnoid block.

The technique of paravertebral block is described in simple and straightforward terms. With the patient semiprone or on his side, a $10 \mathrm{~cm}$. needle is introduced three fingers' breadth from the midline at an angle of $45^{\circ}$ to the skin surface. As it advances, it is either held up by the rib or passes through the intercostal space until it strikes the body of the vertebra in the true paravertebral space. After withdrawal of the needle for a couple of millimetres, 5 to $10 \mathrm{ml}$. of solution are injected. The considerable danger of entering the subarachnoid space through the intervertebral foramen is pointed out.

Other techniques described and beautifully illustrated are intercostal, iliac crest, posterior splanchnic and lumbar sympathetic blocks.

This book brings up to date the earlier work of Labat (1930) and Norman James (1943). It is marked by simple common sense born of great elinical experience. All anaesthetists must, and abdominal surgeons should, read this most excellent and practical monograph. 